\title{
La tesis bio-antropología del innatismo Falacias descubiertas desde la reflexión filosófica acerca de la experiencia moral
}

\author{
Bio-anthropological thesis of innatism \\ On the fallacies discovered through \\ philosophical reflection on the moral experience \\ ÓSCAR BARROSO FERNÁNDEZ \\ Universidad de Granada
}

Recibido: 14/03/2013 Aceptado: 18/09/2013

\begin{abstract}
RESUMEN
En los últimos años se observa una tendencia a recuperar la tesis del innatismo moral desde el ámbito de las ciencias bio-antropológicas. Dicha tesis encuentra apoyo en el descubrimiento de ciertos universales morales y en la constatación de la capacidad humana de producir respuestas morales de forma inmediata. El autor de este trabajo, aun cuando considera plausible que en la conducta moral haya elementos innatos, mantiene que las pruebas aducidas incurren en la falacia del falso dilema: respecto a los universales morales, pueden ser alcanzados racionalmente; respecto a las respuestas morales inmediatas, pueden ser resultado de un proceso de habituación. Para demostrar el carácter falaz de estas demostraciones, el autor se apoyará en la antropología moral de Zubiri.
\end{abstract}

PALABRAS CLAVE

ANTROPOLOGÍA BIOLÓGICA, INNATISMO, UNIVERSALES MORALES, EXPERIENCIA MORAL, ZUBIRI

\section{ABSTRACT}

Recently, we have been witnessing a tendency to bring back to life the thesis of moral innatism, mainly due to the support of bio-anthropological sciences. This thesis is based on the discovery of some moral universals on the one hand, and on the affirmation of human capacity to produce

(C) Contrastes. Revista Internacional de Filosofia, vol. XIX-N² (2014), pp. 339-355. ISSN: 1136-4076

Departamento de Filosofía, Universidad de Málaga, Facultad de Filosofía y Letras Campus de Teatinos, E-29071 Málaga (España) 
moral answers in an immediate way on the other. The author of the present paper assumes that it is plausible that there are some innate elements in human behavior; nevertheless, he argues that arguments in favor of this statement fall into the so called false dilemma fallacy. As to the moral universals, they can be approached in a rational way; as to the immediate moral answers, they could be a result of habituation process. The author bases his demonstration of these fallacies on the moral anthropology of Xavier Zubiri.

KEY WORDS

BIOLOGICAL ANTHROPOLOGY, INNATISM, MORAL UNIVERSALS, MORAL EXPERIENCE, ZUBIRI

\section{INTRODUCCIÓN}

EN ESTE TRABAJO VOY A ANALIZAR algunas repercusiones filosóficas de los avances habidos en los últimos años en el estudio científico de la naturaleza humana, sobre todo desde la genética y la neurociencia. Me centraré en dos argumentos que suelen utilizarse en favor de la existencia de elementos innatos en el comportamiento moral.

En primer lugar, dado que es posible constatar experimentalmente la existencia de universales morales y dado que si todo lo moral fuera de origen cultural no sería posible que estos existieran, necesariamente son de carácter innato.

En segundo lugar, también puede probarse científicamente que los seres humanos responden inmediatamente a muchos conflictos morales y dado que la elección racional exige mediación, las respuestas inmediatas son necesariamente innatas.

Creo que con independencia de estos argumentos hay elementos suficientes para constatar que nuestra moral está condicionada por nuestra biología o, dicho de otra forma, que nuestra naturaleza humana no es maleable en términos absolutos. Pero al mismo tiempo considero que las argumentaciones basadas en la universalidad y la inmediatez observable en la conducta del ser humano incurren en la falacia del falso dilema. Cabe la posibilidad de que los principios morales universales y las acciones inmediatas tengan su causa en factores distintos al innatismo. De hecho, un somero acercamiento a la historia de la filosofía muestra contundentemente que estamos ante algo más que una mera posibilidad. Partiendo de la antropología de Xavier Zubiri, sostendré que tanto la universalidad como la inmediatez en moral pueden ser explicadas filosóficamente en base a la dinámica propia de la experiencia racional moral y los mecanismos en ella implicados.

Intentaré demostrar esta tesis a través de los siguientes pasos:

En primer lugar, dado que mí crítica al innatismo bio-antropológico no constituye una recusación total de los condicionantes biológicos de la natura- 
leza humana, rechazaré la acusación simplista de determinismo que desde la filosofía y las ciencias sociales se suele lanzar contra la biología en este punto.

En segundo lugar, mostraré la importancia que tienen los descubrimientos científicos respecto de la naturaleza humana para una adecuada comprensión del comportamiento moral, en tanto que este siempre se efectúa de acuerdo a una determinada idea del ser humano.

En tercer lugar, y ya en referencia a las falacias cometidas en los intentos de argumentación a favor del innatismo moral, me detendré en el análisis de la conexión que suele establecerse entre principios morales universales e innatismo.

En cuarto lugar, mostraré que en este caso la caída en la falacia del falso dilema tiene a su base una comprensión deficiente de la racionalidad en el ámbito de lo moral.

En quinto lugar analizaré la conexión que se establece entre decisiones morales inmediatas e innatismo y demostraré que en este caso el falso dilema surge por la ignorancia de una problemática filosófica fundamental: la conducta conforme a hábitos.

Desde un punto de vista metodológico, mi confrontación no se mueve en la primera línea de la investigación bio-antropológica, es decir, no toma en cuenta directamente trabajos experimentales concretos en los ámbitos de la genética y la neurociencia, sino que se mide con trabajos monográficos sintéticos e, incluso, divulgativos. Esta decisión metodológica tiene dos razones de ser. En primer lugar, el reconocimiento de las lagunas inherente a mi acercamiento filosófico, no técnico, a estas complejas cuestiones. En segundo lugar, la percepción de la riqueza filosófica propia de estos trabajos monográficos: al intentar hacerse cargo de lo humano en una perspectiva más global que la que ofrecen los concretos trabajos experimentales, los autores de estas monografías, aún cuando provienen del ámbito de especialización científica, se ven obligados a echar mano de conceptualizaciones filosóficas. Esto ha de resultar fundamental en tanto que mis objeciones no son tan temerarias como para oponerse a resultados científicos, sino a ciertas conclusiones filosóficas que se extraen desde estos resultados. Por lo demás, como indicaba más arriba, mi enfoque filosófico se construirá partiendo de la antropología de Zubiri.

\section{BIOLOGÍA Y MORAL: MÁS ALLÁ DEL DETERMINISMO}

Desde la publicación de Sociobiología ${ }^{1}$ por parte de Edward O. Wilson, los estudios sobre los condicionantes biológicos de la conducta humana han progresado enormemente. En la actualidad, no se trata sólo de analizar, de la mano de la psicología evolucionista y la genética conductual, los aspectos genéticos decantados evolutivamente que permiten hacer referencia a patrones de

1 Cf. E. O. Wilson, Sociobiology: The New Synthesis, Harvard University Press, 1975. 
conducta innatos en los seres humanos, sino que la cuestión ha sido reforzada a partir de la revolución producida en el campo de las ciencias neurológicas. ${ }^{2}$

Las implicaciones filosófico-morales que tienen los recientes descubrimientos en el marco de las ciencias bio-antropológicas son algo más que meras curiosidades externas al quehacer propio de estas ciencias. Dichas implicaciones constituyeron el núcleo de la sociobiología y dan sentido a un nuevo ámbito de conocimiento: el de la «neuroética». El término apareció planteado de forma modesta por William Safire con el objetivo de designar «el ámbito de la filosofía que trata sobre los aspectos buenos y malos del tratamiento o la potenciación del cerebro humano». ${ }^{3}$ Desde esta perspectiva, la neuroética es una derivación de la bioética, de la ética médica, que afecta a áreas de la ingeniería genética, la ciencia reproductiva o la definición de la muerte cerebral.

El neurólogo Michael S. Gazzaniga ha ido más allá de esta versión de la neuroética como ética aplicada al entender que se trata de un saber global, teórico y práctico a la vez: «la neuroética debe definirse como el análisis de cómo queremos abordar los aspectos sociales de la enfermedad, la normalidad, la mortalidad, el modo de vida y la filosofía de la vida, desde nuestra comprensión de los mecanismos cerebrales subyacente. Esta disciplina no se dedica a la búsqueda de recursos para la curación médica, sino que sitúa su responsabilidad personal en un contexto social y biológico más amplio. Es $-\mathrm{O}$ debería ser- un intento de proponer una filosofía de la vida con un fundamento cerebral». ${ }^{4} \mathrm{~A}$ juicio de Gazzaniga, en base a este fundamento cerebral, la neuroética podría, hipotéticamente, permitir el desarrollo de una ética de carácter universal: «podría existir un conjunto universal de respuestas biológicas a los dilemas morales, una suerte de ética integrada en el cerebro». ${ }^{5}$

¿Qué tiene que decir la filosofía respecto del intento de fundar la ética en la neurociencia? La nefasta recepción que hizo de las pretensiones de la sociobiología puede ayudarnos a saber qué hemos de evitar para lograr una articulación positiva entre filosofía y ciencias bio-antropológicas con el objetivo de alcanzar una mejor comprensión del comportamiento moral.

2 Una muestra paradigmática de las aplicaciones que dicha revolución tiene para la comprensión de la conducta humana, la encontramos en la obra de Antonio Damasio, En busca de Spinoza. Neurobiología de la emoción y los sentimientos (Barcelona: Crítica, 2005). Cf. O. Barroso: «¿Cómo construir un modelo integral del ser humano desde la antropología filosófica? A propósito de las implicaciones éticas y políticas del enfoque neurocientífico de Damasio», en J. San Martín y T. D. Moratalla (eds.), Perspectivas sobre la vida humana. Cuerpo, mente, género y persona, Madrid: Biblioteca Nueva, 2011, pp. 103-111.

3 «The Risk That Failed», New York Times, 10 de julio de 2003.

4 M. S. Gazzaniga, El cerebro ético, Barcelona: Paidós, 2006, pp. 14-15.

5 Ibid., p. 17. 
Efectivamente, hubo, por parte de la filosofía y las ciencias sociales, una recusación total del intento sociobiológico de encontrar las bases genéticas, decantadas evolutivamente, de la conducta. Es cierto que la retórica polémica de autores como Dawkins o Wilson no ayudó a la asimilación de sus interesantes resultados; pero no es menos cierto que el rechazo total, fundado en un supuesto determinismo, fue injusto con la sociobiología, que aceptaba que los resultados de la biología son estadísticos y que los rasgos biológicos normalmente son resultado de la influencia combinada de factores genéticos y ambientales. De tal forma que la influencia que los genes ejercen sobre la conducta es meramente estadística. Influencia que, por lo demás, puede ser modificada, incluso anulada, por otras influencias. Entre ellas, nuestra propia libertad. Como el teórico evolucionista David. N. Stamos escribe, «podemos rebelarnos contra ellos»». ${ }^{6}$

También Steven Pinker ha defendido al evolucionismo de la acusación de determinismo a través de la distinción entre causa próxima y remota. ${ }^{7}$ Si por determinismo se entiende cualquier grado de tendencia en las personas a actuar de una determinada forma en una determinada circunstancia, estas doctrinas son deterministas. Pero parece exagerado sostener tal posición, según la cual «el innatismo cero es la única creencia aceptable».8

Aún cuando la bio-antropología ha sabido situarse más allá de un burdo determinismo, la filosofía sigue enrocada en sus posiciones tradicionales: la ignorancia y el rechazo.

En parte a causa de ello han sido los propios científicos los que se han lanzado a extraer conclusiones filosófico-morales a partir de los descubrimientos bio-antropológicos. A este respecto, la sofisticación de la tesis del innatismo es tan grande que ha vencido con rotundidad a su contraria: la tesis de la tabula rasa (la idea de que la mente humana carece de una estructura inherente; lo que posibilita que la sociedad, cuando no nosotros mismos, pueda escribir sobre ella a voluntad); aunque desde las ciencias sociales, las humanidades e, incluso, «lo políticamente correcto» tienda a ignorarse la derrota sufrida y se siga defendiendo esta tesis. Hoy, como ha visto Stamos, el rechazo de elementos innatos en la naturaleza humana es difícilmente sostenible: «el Homo sapiens no es solamente una especie que ha surgido como un fruto de la evolución biológica, sino también una especie social, una especie que evolucionó en el marco de pequeños grupos de cazadores-recolectores. En este sentido, sería

6 D. N. Stamos, Evolución. Los grandes temas: sexo, raza, feminismo, religión y otras cuestiones, Barcelona: Biblioteca Buridán, 2009, p. 64.

7 S. Pinker, La tabla rasa. La negación moderna de la naturaleza humana, Barcelona: Paidós, 2003, p. 173.

8 Ibid., p. 178. 
realmente sorprendente que como especie animal que es, la evolución no le hubiera dotado de una serie de instintos especiales como ha hecho con las demás especies». ${ }^{9}$

\section{NATURALEZA HUMANA E IDEAS DE SER HUMANO}

Zubiri ha sostenido que la variabilidad sociocultural que podemos observar en los sistemas de bienes y deberes pende de diversas ideas de ser humano: «En el fondo lo que late es no un problema de multiplicidad de deberes, sino una cosa más grave y radical: una multiplicidad pavorosa de ideas precisamente acerca de lo que es el hombre [...] Ni el individuo ni la sociedad pueden determinar un sistema de deberes, si no es en vista de una cierta idea del hombre». ${ }^{10}$

Las ideas de ser humano no son ficciones, ya que tienen carácter real; se construyen de acuerdo a lo que efectivamente es aquél. Pero, al mismo tiempo, tampoco se reducen a una descripción de lo que el ser humano es, sino que incorporan lo que puede llegar a ser. Las ideas acerca del ser humano son, al mismo tiempo, también ideales.

Las ideas sobre el ser humano no son meras curiosidades, sino elementos fundamentales para la supervivencia de éste: no puede subsistir más que estando sobre sí con una idea de sí mismo. Como afirma Zubiri, en el caso del hombre, «su propia idea pertenece a su propia realidad». ${ }^{11}$ Las distintas ideas de ser humano no dan lugar, obviamente, a distintas realidades humanas, pero sí a distintas ideas de perfección, distintas ideas de qué es la naturaleza humana $\mathrm{y}$, consecuentemente, qué es lo que puede «dar de sí».

Si aceptamos este nivel antropológico de la moral, al que Aranguren, siguiendo a Zubiri, llamó «moral como estructura», ${ }^{12}$ es obvio que las ciencias antropológicas deben constituir elementos fundamentales de reflexión para todo planteamiento ético o político.

No exagera Pinker cuando afirma que «las teorías opuestas de la naturaleza humana se entrelazan en diferentes maneras de vivir y diferentes sistemas

9 D. N. Stamos, Op. cit., p. 22.

10 X. Zubiri, Sobre el hombre, Madrid: Alianza, 1986, p. 425. Obviamente, esta tesis no constituye una gran novedad filosófica. Desde un punto de vista histórico, fue defendida paradigmáticamente por Aristóteles y Spinoza; y en el ámbito de la Antropología Filosófica producida en el siglo XX en España, el tema es una constante. Cito sólo a modo de ejemplos los siguientes casos: J. D. García Bacca, Antropología Filosófica Contemporánea, Barcelona: Anthropos, 1982, cap. III; J. Chozas, Manual de antropología filosófica, Madrid: Rialp, 1988, p. 16; J. San Martín, El sentido de la filosofía del hombre. El lugar de la antropología filosófica en la filosofía y la ciencia, Barcelona: Anthropos, 1988, cap. IV; C. Beorlegui, Antropología filosófica. Nosotros: urdimbre solidaria y responsable, Universidad de Deusto, 1999, p. 167.

11 X. Zubiri, Op. cit., p. 429.

12 J. L. L. Aranguren, Ética, Madrid: Alianza, 1958, p. 88. 
políticos, y han sido causa de grandes conflictos a lo largo de la historia». ${ }^{13} \mathrm{Y}$ lo cierto es que si estas teorías han sido propuestas tradicionalmente desde la religión y la filosofía, hoy sería absurdo pretender una comprensión cabal de la naturaleza humana sin contar con los resultados de las ciencias naturales.

Pero aún toda la evidencia a favor de los distintos elementos que configuran biológicamente nuestra naturaleza, la filosofía ha tratado continuamente de echar por tierra cualquier propuesta innatista, por moderada que fuera. Las razones para ello son múltiples.

En primer lugar, este rechazo se ha producido en base a una especie de miedo a la inmoralidad. A grandes rasgos, se ha partido de la idea de que la negación de la tabula rasa nos convertiría en seres irremediablemente egoístas e inmorales. Pero lo cierto es que, más allá de lo falaz de tal argumentación, ${ }^{14} \mathrm{si}$ las teorías morales se fundan en ideas sobre la naturaleza humana y si resultara que estamos constituidos por una naturaleza más determinada, su negación sería contraproducente, en tanto que impediría una adecuada actuación moral y política. La primera exigencia de una idea moral o política es que se adecue a lo que sabemos sobre la naturaleza humana; que parta de una comprensión correcta del ser humano.

Como las ideas de humanidad no se agotan en lo que el ser humano es -sino que incorporan también lo que puede llegar a ser (el ámbito de la idealidad)-, «las ideas sobre la naturaleza humana, por sí mismas, no pueden resolver controversias desconcertantes ni determinar la política pública»..$^{15}$ Pero aún así no deja de ser cierto que la concepción que tengamos de la naturaleza humana puede determinar en gran parte nuestras opciones morales y políticas.

Sin duda, hemos de ponderar las pretensiones éticas y políticas destiladas a partir de las ciencias biológicas; hemos de mantener el espíritu crítico y denunciar las ingenuidades y los reduccionismos, pero no podemos dar la espalda a todos estos conocimientos, ni rechazarlos frontalmente. Hacerlo constituiría una irresponsabilidad.

Una segunda explicación del rechazo de la tesis del innatismo moral puede encontrarse en el sentimiento de intrusismo que, llevado al extremo, podría llegar a poner en peligro la institución filosófica: ¿no están neurocientíficos y evolucionistas en condiciones de sacar a los filósofos del mercado de la ética? ¿Acaso no parece apuntar todo lo dicho a que la ética es sólo un conjunto de funciones propias del cerebro de un primate altamente socializado? En realidad, responder afirmativamente a esta pregunta sería exagerar la potencia teórica en este punto del innatismo. Como ha mostrado, partiendo también del evo-

13 S. Pinker, Op. cit., p. 23.

14 Ibid., pp. 245 y ss.

15 Ibid., p. 291. 
lucionismo, Ehrlich, aunque la capacidad de desarrollar éticas es ciertamente un producto de la evolución, los productos de esa capacidad son en su mayor parte el resultado de la evolución cultural. ${ }^{16}$

Más allá de estas explicaciones del rechazo del innatismo, hemos de insistir en la irresponsabilidad que constituye defender ideas del ser humano construidas a partir de la negación de la existencia de elementos innatos tanto en nuestra comprensión del mundo como en el habitarlo. Por ello la filosofía debe hacerse cargo con rigor de estos descubrimientos. Proponer nuevas ideas de humanidad coherentes con ellos es algo que debe estar en la agenda de la Antropología Filosófica.

Esta es una tarea que a todas luces sobrepasa las posibilidades de este modesto trabajo. En lo que sigue sólo llevaré a cabo una tarea previa. Como decía antes, el primer abordaje filosófico de la cuestión del innatismo biológico se está produciendo por científicos. Aún cuando es de alabar el esfuerzo, también es necesario denunciar que tal abordaje se lleva a cabo con cierta dosis de ingenuidad que hace caer a estos científicos en algunos errores. Como ya indiqué en la introducción, me voy a referir a dos de ellos: la argumentación a favor del innatismo a partir del descubrimiento de universales morales y de la inmediatez con la que respondemos a muchos problemas éticos.

\section{INNATISMO Y UNIVERSALES MORALES}

Los biólogos que han reflexionado sobre la dimensión moral de la naturaleza humana han mostrado un interés especial por saber si en ella hay algo universal. El asunto ha de resultar emblemático para ellos, en contraposición a los científicos sociales (en especial los antropólogos culturales y su tendencia a la defensa del relativismo cultural a lo largo del siglo XX).

Al respecto, lo primero que observamos, tanto en la neurociencia como en la psicología evolucionista y la genética conductual, es la tendencia a equiparar lo universal y lo innato.

Obviamente, no se apunta con ello a máximas precisas; aquello que se manifiesta como universal no puede expresar leyes, costumbres u obligaciones normativas concretas, sino una especie de propensiones simples y generales, de impulsos genéricos. A juicio de Gazzaniga, entre este tipo de impulsos aparece el rechazo del asesinato y el incesto, el cuidado y el no abandono de los niños,

16 P. R. Ehrlich, Naturalezas humanas. Genes, culturas y la perspectiva humana, México: FCE, 2005, pp. 574-575. Ciertamente, la actitud de Ehrlich no es mayoritaria entre los científicos que llevan a cabo incursiones filosóficas a propósito del innatismo. Lo habitual es que estos aún acaben cayendo en posiciones reduccionistas (agravadas en el caso de algunos divulgadores; piénsese, por ejemplo, en la abundante literatura producida por Eduard Punset). Pero el error reduccionista de algunos (o de muchos) no quita un ápice de valor a la tesis innatista. 
la fidelidad a la familia, no mentir y el deber de cumplir las promesas. ${ }^{17}$ Por su parte, Stamos añade la empatía y la compasión. ${ }^{18}$

Una de las supuestas fuentes de confirmación de la existencia de los universales morales y su carácter innato, procede del Moral Sense Test desarrollado por Marc Hauser. ${ }^{19}$ Si los juicios morales nacieran de procesos racionales, las personas de culturas diferentes deberían responder de forma variable a desafíos comunes, y deberían ser capaces de justificar sus respuestas o decisiones de forma convincente. Pues bien, a través de este test, Hauser demostró que la mayor parte de las personas responden tomando decisiones morales muy similares; al mismo tiempo que les resulta tremendamente difícil justificar sus respuestas desde un punto de vista lógico y racional (cuando lo intentaban, más bien proponían interpretaciones personales arbitrarias para salir al paso). Ello parece indicar que hay mecanismos subconscientes comunes a toda la especie humana y que están a la base de las decisiones morales.

Stamos considera que las diferencias culturales en el ámbito moral se sitúan en las creencias y en las variables condiciones de existencia de las culturas, no en los valores, que en sí mismo son de carácter transcultural. ${ }^{20}$ Por ejemplo, cuando los esquimales dejan morir a ancianos y enfermos, no es que valoren la vida menos que nosotros. Simplemente, sus condiciones de existencia son tan duras que no pueden subsistir sin tales prácticas. Si nos fijamos en problemas más próximos, como el debate respecto al aborto, las diferencias que se observan se refieren a la creencia de si el feto es o no un humano, no al valor mismo de humanidad.

Para Stamos, los valores transculturales son el resultado de un proceso de selección: aquellas culturas que carecieran de ellos, no lograrían la cohesión social suficiente para sobrevivir. ${ }^{21}$ Ello significa que los instintos morales han surgido por evolución.

De todo ello parece seguirse, además, que la moral no es una cuestión de razonamientos. Stamos rechaza incluso que «un cambio en las creencias metaéticas represente la más mínima diferencia en la conducta moral».22 Y continúa: «la mayoría de la gente, la mayor parte del tiempo, no razona en absoluto cuando se comporta moralmente. Simplemente siguen las normas de su sociedad, a menudo combinándolas con instintos como el de la compasión». ${ }^{23}$

17 M. S. Gazzaniga, El cerebro ético, Op. cit., pp. 169-170.

18 D. N. Stamos, Op. cit., p. 254.

19 http://moral.wjh.harvard.edu/v2/Spanish/index.html

20 Ibid., p. 242.

21 Cf. J. Rachels, The Elements of Moral Philosophy, Nueva York: McGraw-Hill, 2003.

22 D. N. Stamos, Op. cit., p. 254.

23 Ibid., p. 256. 
La justificación última de la moral sólo puede lograrse desde la teoría de la evolución. El razonamiento de Stamos es el siguiente: «Justificarlas con otras razones nos lleva a una regresión infinita. Al final, hay que detenerse en unas verdades evidentes por sí mismas, en el relativismo cultural del Modelo Estándar de las Ciencias Sociales, o en la biología evolutiva. Parece poco probable que la moralidad se reduzca en el fondo a unas verdades necesarias, al modo de los axiomas geométricos, y recurrir al relativismo cultural no es en absoluto una auténtica justificación. Lo que nos queda, pues, al menos, es una especie de Hume darwinizado». ${ }^{24}$

La conclusión no se deja esperar: «la moralidad en los humanos no es algo socialmente construido y básicamente racional, ni divinamente revelado, sino que tiene un núcleo o denominador común que es un producto de nuestro pasado evolutivo en grupos de cazadores-recolectores. En este sentido, la moralidad no es algo absoluto (eterno e inmutable), ni algo personalmente subjetivo (algo que dependa de lo que piense cada individuo), pero sí algo objetivo, en el sentido de que los rasgos adaptativos de una especie son objetivos».25

\section{RAZÓN Y MORAL}

La primera condición para que los teóricos del innatismo puedan afirmar que una conducta universal debe estar apoyada en un componente innato, se encuentra en la paradójica aceptación (conocida la habitual confrontación entre las «dos culturas») del relativismo cultural de las creencias defendido desde ciertos ámbitos de las ciencias sociales. Pero entonces la presunción de un mínimo de conexión entre las creencias y la realidad objetiva echaría por tierra la supuesta relación necesaria y condicional entre universalismo e innatismo.

En alianza con los relativistas radicales de las ciencias sociales, los innatistas parecen presuponer que la racionalidad moral se halla totalmente desconectada de la realidad objetiva; ${ }^{26}$ es decir, que frente a otras formas de racionalidad práctica (como la técnica), que tienen como objetivo lograr la respuesta más adecuada a los problemas que la realidad presenta, la racionalidad moral sería incapaz de superar los marcos concretos de la cultura en que se ha generado, con lo que las creencias morales serían absolutamente relativas a las

24 Ibid., p. 257.

25 Ibid., p. 262.

26 Son muchas las críticas que pueden ser lanzadas contra el concepto de racionalidad moral que habitualmente manejan estos científicos. Partiendo del reduccionismo con que los neuroéticos suelen tratar la racionalidad moral, Adela Cortina ha desarrollado una crítica filosófica en base a una concepción multidimensional de lo que significa la vida moral y que, en parte, se hace cargo de lo que yo mantengo en este trabajo. $C f$. A. Cortina, «Neuroética: ¿Las bases cerebrales de una ética universal con relevancia política?», Isegoría: Revista de Filosofía Moral y Política, 42 (2010), 129-148. 
culturas en que se producen. Pero lo cierto es que las creencias morales forman parte de un tipo concreto de experiencia racional que, como toda experiencia racional, implica una posibilidad de probación en la realidad. Para explicar esta tesis me apoyaré, de nuevo, en Zubiri. ${ }^{27}$

La razón moral comparte con el resto de formas de racionalidad el empeño por comprender y responder lo mejor posible a los problemas que la realidad nos plantea. Pero entonces también ha de participar del dinamismo de universalización de toda verdad racional.

El relativista sitúa el relativismo en los sistemas de deberes morales, pero en realidad los deberes son relativos a determinadas ideas del ser humano (que incluyen, como sabemos, ideales, ideas de perfección), y estas ideas se han de medir efectivamente con la realidad..$^{28}$ Como en sus otras dimensiones, en la moral la razón también está sometida a la experiencia. Obviamente, esta experiencia se distingue del «experimento» científico; consistiendo ahora en «compenetración»-entre personas y entre culturas- o «conformación»-la experiencia que adquiere la propia realidad personal a lo largo de su decurso vital o, socialmente, la experiencia que adquiere una cultura a lo largo del decurso histórico. Pero en todo caso, las ideas de humanidad, los esbozos morales, pueden ser probados en la realidad y contrastados entre sí; pueden así ir verificándose o, en su caso, ser falsados. En el ámbito de la moral hay, por lo tanto, verdad.

El ser humano necesita desarrollar esbozos morales y comprobar si se ajustan a la realidad. ${ }^{29}$ Para Zubiri, dado que las ideas no son adventicias al ser humano, se ha de investigar en qué medida cada una de ellas se ajusta a la perfectibilidad de la que es capaz por su propia constitución psicofísica: «La

27 Aquí sólo puedo mostrar la posición de Zubiri al respecto en sus líneas maestras. Para un tratamiento más riguroso de la cuestión véase: $\mathrm{O}$. Barroso, «La experiencia moral: una ética sin verdades absolutas», www.youtube.com/watch? $\mathrm{v}=\mathrm{hvjVn-90Pjw}$.

28 El problema de estos autores es que han desterrado completamente del ámbito de la moral el asunto de los ideales de realización; como muestra el hecho de que para Gazzaniga la diferencia entre «moral animal» y humana resida «en la mayor diversidad y complejidad de las emociones morales que tenemos los humanos [...] y en las conductas a las que estas emociones contribuyen». M. S. Gazzaniga, ¿Qué nos hace humanos? La explicación científica de nuestra singularidad como especie, Barcelona: Paidós, 2010, p. 167.

29 La moral surge como el puente necesario entre estímulo y respuesta en la vida humana, dada la falta de programación innata de nuestras respuestas. Mientras que hay un perfecto ajustamiento entre los estímulos sentidos por el animal y las respuestas dadas, el ser humano se ve continuamente en la necesidad de hacer el ajustamiento; de justificar su respuesta. Seguramente es exagerado ver en la conducta animal sólo patrones instintivos y en la humano sólo patrones inteligentes, pero qué duda cabe que mientras que la mayor parte de la conducta animal se puede explicar por instintos, la mayor parte de la conducta humana sólo se puede explicar por la apertura inteligente a la realidad. 
perfección humana está fundada en una perfectividad y precisamente por eso esas distintas ideas del hombre representan otras tantas 'posibilidades' de ser hombre de una manera o de otra [...] A hora bien, si las distintas ideas del hombre están en lo que es el hombre de una manera incoativa, cada una de esas ideas tiene que medirse con la perfectividad interna del hombre». ${ }^{30}$ Los cambios en las ideas del ser humano parten de lo que este es en su sustantividad por su dimensión de perfectividad. La conclusión va a ser terminante: «El aparente relativismo no es sino un desarrollo de posibilidades, algo que no hace sino desplegar posibilidades que incoativamente están en la propia sustantividad humana [...] Todas esas posibilidades están ancladas en lo que el hombre es por su sustantividad. Por tanto, todas esas perfecciones, todas esas ideas o tipos posibles de perfectividad que hay en el hombre, penden, en última instancia, de lo que constituya la razón de ser de la propia sustantividad humana». ${ }^{31}$

En realidad, la posibilidad de alcanzar, de acuerdo a los mecanismos de la racionalidad moral, principios morales universales, es algo con fundamento incluso en el planteamiento de muchos de aquellos que han hecho depender el universalismo del innatismo. En el caso concreto de Pinker, la justificación del carácter innato de los patrones universales de comportamiento a partir de la aceptación del relativismo de las creencias, resulta contradictoria si atendemos a pasajes como el siguiente: «la cultura es un fondo común de innovaciones tecnológicas y sociales que las personas acumulan para que les ayuden a vivir la vida, no una colección de roles y símbolos arbitrarios que sobrevienen. Esta idea ayuda a explicar qué hace diferentes y similares a las culturas». ${ }^{32}$ Ello significa, para Pinker, que aunque hoy la identidad cultural es un valor, lo cierto es que las culturas siempre han sido porosas (se trata de la verdad como encuentro a la que me refería antes) y han estado en constante movimiento; este movimiento se ha acelerado, obviamente, en aquellos momentos en que más información han tenido los miembros de una cultura acerca de otras. En este sentido, las culturas funcionan como herramientas para la vida. Por ello, unas culturas tienen más éxito material que otras en tanto que están objetivamente mejor adaptadas al medio. Las culturas compiten entre sí como formas mejores o peores de hacer las cosas.

\section{HÁBITOS Y MORAL}

Aun cuando la experiencia racional desempeña un papel fundamental en los asuntos morales, lo cierto es que no nos vemos obligados a reflexionar ante cada cuestión moral, sino que, con frecuencia, nuestras respuestas surgen de forma

30 X. Zubiri, Op. cit, pp. 430-431.

31 Ibid., pp. 431-2.

32 Ibid., p. 110.

Contrastes vol. XIX-N² (2014) 
inmediata e irreflexiva. Pero aunque no dudo en que en este tipo de respuestas intervienen ciertas disposiciones innatas, considero que tanto o más importantes que estas disposiciones son los hábitos. El asunto ha sido fundamental para la comprensión de la naturaleza humana al menos desde la filosofía de Aristóteles, pero se trata de una cuestión ignorada en las investigaciones antropológicas que parten de la neurología y el evolucionismo. ${ }^{33}$ Para estos científicos, dado que se ha demostrado, a través de imágenes de resonancia magnética del cerebro, que, ante determinados juicios y problemas morales, los razonamientos se hallan precedidos por una respuesta automática en el cerebro, no hay duda en que la neurociencia ha confirmado el innatismo de los impulsos.

Ello explica su tendencia a situarse en un falso dilema: o bien la elección moral es dependiente de respuestas innatas o bien es el resultado de una decisión racional. A partir de aquí, al descubrir que en el ámbito de las respuestas humanas a cuestiones morales no todo es decisión racional, sino que se dan respuestas inmediatas, se las hace depender de emociones e intuiciones de carácter innato.

Gazzaniga nos sitúa plenamente en el dilema mencionado: «Por regla general, si un modo de pensar nos viene a la mente con facilidad, es bastante probable que tengamos cierto mecanismo cognitivo que ha sido configurado para hacernos pensar de ese modo». ${ }^{34}$ Es por lo tanto normal que formule las siguientes cuestiones: «Cuando se nos plantea una decisión moral, ¿es nuestro yo racional el que da un paso al frente y toma la decisión, o nuestro instinto, nuestro yo intuitivo, dicta primero el juicio, y nuestro yo racional intenta a continuación aportar las razones? [...] ¿Salimos de la cadena de montaje equipados con un equipo estándar de instintos morales o éstos son accesorios de repuesto?» ${ }^{35}$ La respuesta de Gazzaniga a estos interrogantes es tajante: tenemos una programación ética innata, fruto de la selección natural, aunque haya que admitir que nuestro mundo social determina y convierte estos programas éticos en virtudes. La tesis del innatismo es, según Gazzaniga, incontestable desde el momento en que descubrimos, con Damasio, que las emociones son

33 Aunque aún no ha tenido repercusiones en la forma en que desde el ámbito de las ciencias biológicas se entienden los asuntos morales, J. Schwartz, P. Gaito y D. Lennick («That's the Way We (Used to) Do Things Around Here», Strategy + Business, 62 (2011) (http://www. strategy-business.com/issue62-spring2011)), han analizado cómo los hábitos y las rutinas instalados en las neuronas pueden ser modificados gracias a la plasticidad neuronal, $\mathrm{y}$ han descubierto la importancia que el lenguaje, la verbalización, tiene en este proceso. Pensamos que sus resultados, aplicados en su caso al ámbito de la productividad económica, pueden tener un gran recorrido en su aplicación a los hábitos morales.

34 M. S. Gazzaniga, ¿Qué nos hace humanos?, ed. cit., p. 260.

35 Ibid., p. 126. 
más importantes que las razones en la toma de decisiones. Por ello denomina al procesamiento innato automático «impronta afectiva». ${ }^{36}$

Desde esta perspectiva, la reflexión moral parece solo un elemento decorativo respecto al «verdadero» sentido de la moral: «nuestra especie reacciona de modo instintivo ante los acontecimientos, y en un sistema especializado del cerebro humano se interpreta esa reacción». ${ }^{37}$ Es decir, la partida moral se ha jugado mucho antes de que intervenga la razón: «en nuestra especie la mente tiene un núcleo fijo de reacciones ante los desafíos de la vida, y que atribuimos una moralidad a esas reacción después del hecho». ${ }^{38} \mathrm{O}$, como afirma más adelante: «Cada vez que el cerebro izquierdo procesa información que no coincide con la propia imagen, el conocimiento o el marco conceptual del individuo, el intérprete del hemisferio izquierdo inventa una creencia para que toda la información entrante adquiera sentido y concuerde con la idea inicial». ${ }^{39}$

Gazzaniga encuentra una última demostración de la poca relevancia de la razón para la moral en el hecho de que solemos hacer cosas que van claramente en contra de lo más racional, como, por ejemplo, no abandonar a una pareja enferma o dar limosna. ${ }^{40}$

Corroborando lo que hemos dicho en el apartado anterior, los ejemplos que aquí utiliza Gazzaniga son muestra de la pobreza del concepto de razón moral que maneja, reducido a mero cálculo pragmático.

Aparte de las potencias experienciales y veritativas de la razón moral, en ella intervienen multitud de aspectos que son sencillamente ignorados por $\mathrm{Ga}-$ zzaniga, como por ejemplo el de considerar a los demás como fines y no como medios, o el de tratar a los demás como querríamos que nos trataran a nosotros.

La razón moral no interviene sólo ni fundamentalmente de forma puntual, en decisiones concretas, para solucionar, por ejemplo, determinados dilemas éticos, sino que se halla a la base de nuestros hábitos, constituyendo un elemento fundamental para la conformación de nuestra realidad personal. Como ya hemos visto, la razón moral obedece prioritariamente a la necesidad de los humanos de proyectar ideas de humanidad, ideales de perfección y realización.

Obviamente, no podríamos vivir teniendo que decidir racionalmente a cada momento la respuesta adecuada de acuerdo a nuestros proyectos de realización. Los hábitos, en tanto que configuradores de nuestro carácter, resultan por ello fundamentales. ${ }^{41}$

36 Ibid., p. 133.

37 Ibid., p 152.

38 Ibid., p. 153.

39 Ibid., p. 156.

40 Ibid., p. 142.

41 En lo que sigue voy a hacer uso de algunas ideas que he tratado con más detenimiento en «Persona, religación y realidad moral. Los conceptos éticos a la luz de la filosofía de Zubiri», 
Zubiri afirma que «en todo acto de voluntad el hombre se realiza».42 $\mathrm{Al}$ apropiarse volitivamente una realidad, lo que está haciendo es realizarse a sí mismo. La moral está precisamente constituida por las posibilidades que el ser humano, volitivamente, se apropia. Y por estas propiedades es una realidad moral: «Este conjunto de propiedades apropiadas [...] hacen del hombre una realidad, además de física, moral. [...] La apropiación es constitutivamente la forma más radical y elemental de la moral».43

En esta apropiación se va configurando la personalidad de cada individuo. Todas las preferencias, todos los actos que ejecuta, se inscriben en el decurso de su vida. Cada una de estas acciones va perfilando su figura. En cada acto de elección, la acción pasa, pero la posibilidad queda apropiada. Las posibilidades que me apropio se constituyen como propiedades de mi realidad. Lo radical de la moral está en la voluntad, en el acto en el que digo: «esto es lo que quiero, real y efectivamente», tomando la realidad como posibilidad para dar definición a mi personalidad. Así, en cada acto de apropiación de posibilidades lo que me estoy apropiando es mi propia realidad.

Este definir mi propia personalidad no es una cuestión meramente vivencial, sino algo físico en el sentido de que las propiedades apropiadas definen mi carácter.

El carácter es posible gracias a que cuando una volición pasa, cuando deja de ser actual, queda algo; es decir, que la volición queda formando parte de la realidad que quiere la realidad humana en cuanto momento del proceso de personalización.

Es en el intento de explicar este proceso cuando Zubiri recurre a los hábitos. Las respuestas que damos quedan naturalizadas como hábitos, que facilitan nuestra actuación en futuras situaciones similares. Precisamente podemos entender por virtud la tendencia a dar una respuesta inmediata adecuada gracias al hábito decantado en nosotros por un esfuerzo moral previo: el hombre puede «potenciar su propia capacidad de querer». ${ }^{44}$ Es lo que Zubiri llama «esfuerzo». Con ello está apuntando a la responsabilidad moral en sentido radical: si por la apropiación que el ser humano concretamente efectúa se va configurando su carácter moral, éste será «aquello que efectivamente ha querido ser». Cada uno es «responsable» de su propia figura.

Aunque nuestra existencia está cargada de fatalidades naturales y sociales, queda un resquicio para la responsabilidad en lo que a la formación de nuestro carácter se refiere. Una vida virtuosa es aquella que no desiste en el esfuerzo por

Pensamiento, 246 (2009), pp. 781-807.

42 X. Zubiri, Sobre el sentimiento y la volición, Madrid: Alianza, 1992, p. 70.

43 X. Zubiri, Sobre el hombre, ed. cit., pp. 143-144.

44 X. Zubiri, Sobre el sentimiento y la volición, ed. cit., p. 78. 
lograr el mejor carácter posible; que disponga la existencia a su perfección, al desarrollo de un ideal de humanidad realizada. Seguramente existen en nuestro organismo disposiciones innatas a dar determinadas respuestas inmediatas, pero muchas veces dichas respuestas penden de nuestra experiencia moral previa y en base a ello podemos hablar de respuestas virtuosas o viciosas. El diccionario de la RAE recoge dos sentidos del término «vicio» que expresan a la perfección lo que quiero decir: «falta de rectitud o defecto moral en las acciones» $\mathrm{y}$ «hábito de obrar mal». Obviamente, es preciso descargar los términos de virtud y vicio de toda connotación moral religiosa en particular y heterónoma en general. Los malos hábitos no lo son respecto de un ideal de vida revelado, dado trascendentalmente o impuesto desde fuera, sino respecto de aquel ideal que cada humano debe darse en su ser interior.

Según esta perspectiva, la moral no ha de ser entendida como una cuestión de decisiones o de intuiciones, sino de trabajo continuo sobre nuestra propia realidad en el intento de realizar, de forma virtuosa, un ideal de felicidad. De nuevo, no se trata de una novedad zubiriana. Es lo que estaba a la base de la noción aristotélica de héxis aplicada a cuestiones morales o en la distinción, por parte de Spinoza, entre pasiones positivas y negativas, y su concepción de la vida moral como el esfuerzo de cada ser humano por depender cada vez menos de las pasiones negativas y cada vez más de la positivas y las acciones. ${ }^{45}$

Podemos entender las respuestas inmediatas, más allá de los términos en que lo hace el innatismo, como el resultado del hábito y, en los casos morales virtuosos, del esfuerzo por configurarse uno a sí mismo. ${ }^{46}$ Esto no significa que todo hábito esté sustentando sobre decisiones racionales personales. Muchas veces tomamos como nuestras respuestas que tienen una fuerte presión social, sin meditar sobre su conveniencia para nuestro ideal. Incluso muchos individuos pasan por la vida sin cuestionarse siquiera cuál es el ideal de felicidad con que conducen sus vidas. Pero aún cuando sería imposible pretender fundar una vida sobre una moral basada, en todos sus pasos, en decisiones racionales tomadas personalmente, y aún cuando es cierto que la creación de ideales de realización

45 Cf. I. Hoyos, Naturalismo y pasión en la filosofía de Spinoza. Las fuentes antiguas de la teoría spinozista de las pasiones, Granada, 2011 (Tesis Doctoral).

46 Por lo demás, también desde los hábitos pueden comprenderse otros aspectos de la vida moral explicados por los científicos desde el innatismo. Así, la dificultad de un individuo para justificar racionalmente sus respuestas morales, puede tener diversas causas: el olvido del tipo de decisión que se hallaba a la base del hábito constituido; la existencia de un hábito vicioso; o la falta de reflexión previa a la constitución del hábito. A su vez, el descubrimiento de que los cambios en las creencias metaéticas no producen inmediatamente cambios en el comportamiento moral se puede explicar por la misma presencia de hábitos: una vez que una conducta ha sido naturalizada a través de hábitos, los cambios metaéticos que exigirían su abandono no serán suficientes para que esto se produzca; será necesario un nuevo esfuerzo de habituación. 
está reservada a un pequeño número de individuos excepcionales, una moral auténtica sería imposible sin un esfuerzo personal mínimo en este sentido.

Óscar Barroso Fernández es profesor Contratado Doctor en el Departamento de Filosofía II, en la Universidad de Granada.

Linea de investigación

Antropología Filosófica y el Pensamiento Español. Los autores que ha investigado con más profundidad son Francisco Suárez y Xavier Zubiri.

\section{Publicaciones recientes}

«Los entes de razón en Suárez. Una concepción barroca de la realidad», Anales del seminario de historia de la filosofía, 28 (2011), pp. 135-161.

«Accidentes y modos en Suárez. La importancia del Barroco contrarreformista en la configuración de la metafísica moderna», Revista de Hispanismo Filosófico, 17 (2012), 69-88.

«¿Cómo construir un modelo integral del ser humano desde la antropología filosófica? A propósito de las implicaciones éticas y políticas del enfoque neurocientífico de Damasio», en J. S. Martín y T. D. Moratalla (eds.), Perspectivas sobre la vida humana. Cuerpo, mente, género y persona, Biblioteca Nueva, Madrid, 2011.

Dirección electrónica: obarroso@ugr.es 
